\title{
Hot metal wires as sinks and sources of B atoms
}

\author{
Hironobu Umemoto*, Atsushi Miyata
}

Graduate School of Integrated Science and Technology, Shizuoka University, Hamamatsu, Shizuoka 432-8561, Japan

* Corresponding author. Tel/fax: +81 534781275

E-mail address: umemoto.hironobu@shizuoka.ac.jp

\begin{abstract}
Metal wires, such as W, Mo, and Ta, can be boronized to become sinks of B atoms by heating them in the presence of a mixture of $\mathrm{H}_{2}$ and $\mathrm{H}_{3} \mathrm{NBH}_{3}$ or $(\mathrm{BH})_{3}(\mathrm{NH})_{3}$. These boronized wires behave as sources of B atoms when heated in vacuum. The density of B atoms released to the gas phase increases with the addition of $\mathrm{H}_{2}$ and can be more than $10^{11} \mathrm{~cm}^{-3}$, which is enough for surface doping. The release is stable and continues for more than several hours when boronized for $1 \mathrm{~h}$. Since the metal wires are not nitrided, contamination by $\mathrm{N}$ atoms is not expected. $\mathrm{H}_{3} \mathrm{NBH}_{3}$ and $(\mathrm{BH})_{3}(\mathrm{NH})_{3}$ are not explosive, and wires boronized by these species can be used as safe and contamination-free sources of B atoms for surface doping.
\end{abstract}

Keywords: hot-wire; boron atoms; borazane; borazine; surface doping 


\section{Introduction}

In hot-wire technologies, material gases are decomposed on heated wire surfaces to produce radical species, which play key roles not only in deposition but also in etching, surface modification, and doping. One of the largest problems in this technology is aging of the wires through the accommodation of material elements. In general, accommodation causes metal wires to become more brittle and catalytically less active. $\mathrm{W}$, one of the most widely used wire materials, can easily be carburized when exposed to organic material gases [1-5]. Silicidation is a problem when we use $\mathrm{SiH}_{4}$ or organosilicon compounds, although the silicidation by $\mathrm{SiH}_{4}$ is rather minor at high temperatures, i.e., over $1.8 \times 10^{3} \mathrm{~K}$ [3-11]. Metal contamination is another problem. $\mathrm{W}$ wires can easily be oxidized by $\mathrm{O}_{2}$ to produce $\mathrm{WO}_{3-x}$, which has much higher vapor pressure than tungsten metal [12].

On the other hand, there have been several reports on utilizing such chemical reactions of filament materials. For example, Schropp and coworkers took advantage of the oxidation of $\mathrm{W}$ and succeeded in fabricating amorphous as well as nanostructured tungsten oxide films $[13,14]$. Carburization of the wire surfaces is also effective for suppressing $\mathrm{Si}$ accommodation [9]. The accommodation of $\mathrm{B}$ atoms has also been a problem $[15,16]$, but this provides a new technique for doping without using explosive boron compounds [17].

Doping of $\mathrm{B}$ atoms can be accomplished without contamination by decomposing $\mathrm{B}_{2} \mathrm{H}_{6}$ on hot $\mathrm{W}$ wire surfaces [18-20]. The problem is that $\mathrm{B}_{2} \mathrm{H}_{6}$ is not only toxic, but also explosive. Recently, we have shown that borazane $\left(\mathrm{H}_{3} \mathrm{NBH}_{3}\right)$, which is not explosive, can be decomposed well on hot-wire surfaces and that B atoms are produced when decomposed in the presence of $\mathrm{H}_{2}$ [21]. We have also reported that 
an efficient and sustained release of B atoms can be achieved when $\mathrm{W}$ wires boronized by $\mathrm{H}_{3} \mathrm{NBH}_{3} / \mathrm{H}_{2}$ were heated in the presence of $\mathrm{H}_{2}$, even after the termination of the $\mathrm{H}_{3} \mathrm{NBH}_{3}$ supply [17]. Since $\mathrm{W}$ wires are hardly nitrided, the release of $\mathrm{NH}_{x}$ species, and consequently contamination by $\mathrm{N}$ atoms, is not expected. The B-atom density in the gas phase can be increased to more than $10^{11} \mathrm{~cm}^{-3}$, which is sufficient for surface doping.

In the present study, we extend our previous study and discuss the boronization as well as the release mechanisms on the basis of $\mathrm{H}_{2}$ flow rate and wire temperature dependences. Not only W, but also Mo and Ta were examined. $(\mathrm{BH})_{3}(\mathrm{NH})_{3}$, borazine, which has been proposed as a source material of $\mathrm{BN}$ films in hot wire deposition [22], was also tried as a boronizer. The roles of $\mathrm{H}_{2}$ in both the B-atom production processes and the boronization processes are examined as well. It is shown that $\mathrm{B}$ atoms can be released in sufficient quantity for surface doping even in the absence of $\mathrm{H}$ atoms, the efficient etchant of Si substrates [23,24].

\section{Experimental Details}

The experimental procedure and apparatus for this study were similar to those described elsewhere $[16,17,21,25] . \quad \mathrm{H}_{3} \mathrm{NBH}_{3}$ was effused into a cylindrical chamber from its reservoir. $\mathrm{H}_{2}$ or He could be used as a carrier gas, with its flow rate controlled by a mass flow controller (Horiba STEC, SEC-40M). A butterfly valve was set between the reservoir and the chamber so that the $\mathrm{H}_{3} \mathrm{NBH}_{3}$ flow could be shut off. $\mathrm{B}_{2} \mathrm{H}_{6}$ and $(\mathrm{BH})_{3}(\mathrm{NH})_{3}$ were introduced into the chamber after having been diluted with He to $2.0 \%$.

Coiled wires $(30 \mathrm{~cm}$ in length and 0.39 or $0.40 \mathrm{~mm}$ in diameter, Nilaco) were 
boronized by exposure to a mixture of $\mathrm{H}_{2}$ and one of the boron compounds, $\mathrm{H}_{3} \mathrm{NBH}_{3}$, $(\mathrm{BH})_{3}(\mathrm{NH})_{3}$, or $\mathrm{B}_{2} \mathrm{H}_{6}$. The wires were resistively heated with a DC power supply (Takasago, EX-1125H2) up to $2.29 \times 10^{3} \mathrm{~K}$. The wire temperature was measured with a two-wavelength thermometer (LumaSense Technologies, ISR 12-LO). B-atom densities in the gas phase were measured both during and after the termination of the boron-compound supply, using a laser-induced fluorescence technique at $249.77 \mathrm{~nm}$, which corresponds to the $2 s^{2} 3 s^{2} S_{1 / 2}-2 s^{2} 2 p^{2} P_{3 / 2}$ transition. The distance between the wire and the laser beam detection zone was $9 \mathrm{~cm}$. The light source was a dye laser (Sirah, CSTR-LG-18) pumped with a neodymium-doped yttrium aluminum garnet (Nd:YAG) laser (Quanta-Ray, PRO-170). A $\beta-\mathrm{BaB}_{2} \mathrm{O}_{4}$ (BBO) crystal doubled the frequency of the output. The induced fluorescence was detected with a photomultiplier tube (Hamamatsu Photonics, R212UH) through a collimating lens and an interference filter. The photomultiplier signals were processed with a boxcar averager-gated integrator system (Stanford Research Systems, SR240/SR250/SR280) or a digital oscilloscope (LeCroy, HDO4032). The sources and purities of the gases were the same as those reported elsewhere [17,21].

\section{Results and Discussion}

\subsection{Wire aging judged from the electric power consumed}

During boronization, as is shown in Fig. 1, the electric power needed to keep the wire temperature constant increased at first. After $1 \mathrm{~min}$, the power saturated, while the B-atom density still continued to increase. This shows that the emissivity of the wire surfaces is increased by the boronization of the wire surfaces, while the accommodation and release of $\mathrm{B}$ atoms take place simultaneously to reach an equilibrium state. Fig. 1 
also shows the time dependence of the electric power required to keep the wire temperature constant when $20 \mathrm{sccm}\left(1 \mathrm{sccm}=6.9 \times 10^{-7} \mathrm{~mol} \mathrm{~s}^{-1}\right)$ of $\mathrm{NH}_{3}$ was flown. There was no change at all, showing that the nitridation of $\mathrm{W}$ is extremely minor.

3.2 Boron source dependence of the B-atom density

Fig. 2 illustrates the time dependence of B-atom densities in the gas phase in the presence of a $\mathrm{H}_{2}$ flow of $20 \mathrm{sccm}$, measured after boronizing $\mathrm{W}$ wires by $\mathrm{H}_{3} \mathrm{NBH}_{3} / \mathrm{H}_{2}$, $(\mathrm{BH})_{3}(\mathrm{NH})_{3} / \mathrm{He} / \mathrm{H}_{2}$, or $\mathrm{B}_{2} \mathrm{H}_{6} / \mathrm{He} / \mathrm{H}_{2}$. The stable release can be observed for all boronizers and the boron source dependence is minor. It has been confirmed that such release continues for more than $4 \mathrm{~h}$ when boronized by $\mathrm{H}_{3} \mathrm{NBH}_{3} / \mathrm{H}_{2}$ [17]. In these measurements, virgin $\mathrm{W}$ wires were boronized for 60 min with $2.1 \mathrm{~Pa}$ of $\mathrm{H}_{2}$. The $\mathrm{H}_{2}$ pressure during the $\mathrm{B}$-atom density measurement was also $2.1 \mathrm{~Pa}$. The partial pressure of $\mathrm{H}_{3} \mathrm{NBH}_{3}$ was $\sim 0.01 \mathrm{~Pa}$, while those of $(\mathrm{BH})_{3}(\mathrm{NH})_{3}$ and $\mathrm{B}_{2} \mathrm{H}_{6}$ were $0.026 \mathrm{~Pa}$. The wire temperature was kept at $2.29 \times 10^{3} \mathrm{~K}$ during both the boronization and the B-atom density measurement. Absolute densities, evaluated by comparing the signal intensities with that obtained in the presence of $\mathrm{B}_{2} \mathrm{H}_{6} / \mathrm{He}$ and $\mathrm{H}_{2}$, were a little different, but these differences should not be overstressed since uncertainty by a factor two cannot be avoided in the absolute density evaluation. No B atoms could be detected when a virgin wire was heated in the presence of $\mathrm{H}_{2}$, showing that the production of $\mathrm{B}$ atoms from $\mathrm{H}$ atoms and boron compounds deposited on chamber walls is minor.

Boronization with $\mathrm{He}$, without a $\mathrm{H}_{2}$ flow, was also tried, but that was much less efficient for all boron sources. $\mathrm{H}_{2}$ must play a key role, not only in the production processes of B atoms, as discussed in section $\underline{3.4}$, but also in the boronization processes. 
3.3 Wire material dependence of the B-atom density

Fig. 3 shows the wire material dependence after boronization by $\mathrm{H}_{3} \mathrm{NBH}_{3} / \mathrm{H}_{2}$. The relative $\mathrm{B}$-atom densities for $\mathrm{W}, \mathrm{Mo}$, and Ta are plotted against time. In this figure, the relative values, normalized by the density just after the end of the boronization, are plotted for clarity, since the differences in absolute densities were minor. The decay is the slowest for $\mathrm{W}$ and the fastest for Mo, and depended little on the boron sources. In other words, $\mathrm{W}$ is the best for a sink and a source. The decay time for Ta evaluated from the plots in Fig. 3 is $3.6 \times 10^{2}$ min. This may seem to contradict the results of Comerford et al., who reported decay times as short as $23 \mathrm{~s}$ after switching off the $\mathrm{B}_{2} \mathrm{H}_{6}$ flow [15]. It should be noted that what they measured must be the evacuation time of $\mathrm{B}_{2} \mathrm{H}_{6}$. We could also observe such rapid decays just after the termination of the flow of boron-source gases. We measured the time profile after the initial fast decay. In addition, the partial pressure of $\mathrm{B}_{2} \mathrm{H}_{6}$ they employed, 1.3 $\mathrm{Pa}$, was much higher than that in the present work. The B-atom density in their measurement must have been much higher than that observed in the present study and the contribution of released B atoms from wire surfaces must have been less remarkable. As for Mo, the deviation from the exponential decay was large and the lifetime was just estimated to be $\sim 1 \times 10^{2}$ min.

\section{4 $\mathrm{H}_{2}$ flow rate dependence of the B-atom density}

When $\mathrm{W}$ wires boronized by $\mathrm{H}_{3} \mathrm{NBH}_{3} / \mathrm{H}_{2}$ were heated, B-atom density increased with an increase in the $\mathrm{H}_{2}$ flow rate [17]. Similar dependences were observed when wires boronized by $(\mathrm{BH})_{3}(\mathrm{NH})_{3} / \mathrm{He} / \mathrm{H}_{2}$ or $\mathrm{B}_{2} \mathrm{H}_{6} / \mathrm{He} / \mathrm{H}_{2}$ were used. The density in the absence of $\mathrm{H}_{2}$ was $1 / 5$ of that in the presence of a $\mathrm{H}_{2}$ flow of $20 \mathrm{sccm}$. It should be noted that this density in pure He systems without $\mathrm{H}_{2}, 4 \times 10^{10} \mathrm{~cm}^{-3}$ at $2.29 \times 10^{3} \mathrm{~K}$, is still enough 
for surface doping. In other words, it is possible to dope B atoms without exposing $\mathrm{H}$ atoms, the efficient etchant of $\mathrm{Si}$ substrates $[23,24]$. One simple explanation for this $\mathrm{H}_{2}$ flow rate dependence is that $\mathrm{BH}_{x}(1 \leq x \leq 3)$ species are mainly released from boronized wires and $\mathrm{BH}_{x}$ species are converted to $\mathrm{B}$ atoms by reactions with $\mathrm{H}$ atoms formed from $\mathrm{H}_{2}$ in the gas phase [16]. Another possible role of $\mathrm{H}$ atoms in the production of $\mathrm{B}$ atoms will be discussed in section $\underline{3.5}$. Similar $\mathrm{H}_{2}$ flow rate dependences were observed for Mo and Ta, although quantitative measurement was hard for Mo because of its rapid decay. In Ta, the B-atom signal in pure He was much weaker than that in $\mathrm{W}$, showing that the direct ejection of $\mathrm{B}$ atoms is minor.

\subsection{Wire temperature dependence of the B-atom density}

In Fig. 4, B-atom densities are plotted against the reciprocal of the wire temperature for $\mathrm{W}$ and Ta. The Arrhenius plot is almost linear for $\mathrm{W}$, while that for Ta shows a little saturation at high temperatures. For W, the activation energy evaluated from the slope in the absence of a $\mathrm{H}_{2}$ flow, $678 \pm 14 \mathrm{~kJ} \mathrm{~mol}^{-1}$, is larger than that in its presence, $367 \pm 6$ $\mathrm{kJ} \mathrm{mol}^{-1}$. The activation energy in the absence of a $\mathrm{H}_{2}$ flow should represent the energy required to release B atoms directly and is consistent with the calculated adsorption energy of B atoms reported recently, $7 \times 10^{2} \mathrm{~kJ} \mathrm{~mol}^{-1}[26]$. The weak signals when Ta was used in the absence of a $\mathrm{H}_{2}$ flow suggest that the Ta-B bond energy is larger than that for W-B. The apparent activation energy in the presence of a $\mathrm{H}_{2}$ flow should include the contributions of the activation energies to both release $\mathrm{BH}_{x}(1 \leq x \leq 3)$ from wire surfaces and produce $\mathrm{H}$ atoms from $\mathrm{H}_{2}, 2.4 \times 10^{2} \mathrm{~kJ} \mathrm{~mol}^{-1}$ for $\mathrm{W}$ [27]. The apparent activation energy may not be a simple sum of these energies, but the energy required to release $\mathrm{BH}_{x}$ can be estimated to be on the order of $1 \times 10^{2} \mathrm{~kJ} \mathrm{~mol}^{-1}$ for $\mathrm{W}$, 
much less than that needed to release B atoms. The small amount of energy required to release $\mathrm{BH}_{x}$ suggests that non-radical species, such as $\mathrm{BH}_{3}$, are mainly released. $\mathrm{H}$ atoms on wire surfaces may enhance the production and the release of $\mathrm{BH}_{3}$.

\subsection{Comparison with other systems}

It is informative to compare the release processes of $\mathrm{B}$ atoms and $\mathrm{BH}_{x}$ species from $\mathrm{W}$ to the ejection of other species. Winters et al. have reported that $\mathrm{C}$ atoms are released when carburized $\mathrm{W}$ is heated [1]. Since the addition of $\mathrm{H}_{2}\left(\mathrm{D}_{2}\right)$ had no effect on the released $\mathrm{C}$-atom densities, they concluded that the release is simple evaporation. The apparent activation energy they observed, $7 \times 10^{2} \mathrm{~kJ} \mathrm{~mol}^{-1}$, should represent the W-C bond energy. This activation energy is similar to that for the release of B atoms and is consistent with the calculated adsorption energy of $\mathrm{C}$ atoms on $\mathrm{W}$ surfaces, $8 \times 10^{2} \mathrm{~kJ}$ $\mathrm{mol}^{-1}$, reported recently [28]. Si-atom desorption has also been observed from W wires exposed to $\mathrm{SiH}_{4}$ [6]. Holt et al. heated silicided $\mathrm{W}$ under high vacuum and observed $\mathrm{Si}$ atoms mass spectrometrically. The $\mathrm{SiH}_{x}(1 \leq x \leq 4)$ signals were very weak under their conditions. Si atoms must be released by simply breaking W-Si bonds. Tong et al., on the other hand, have shown that $\mathrm{SiH}_{4}, \mathrm{SiCH}_{x}(2 \leq x \leq 5)$, and $\mathrm{SiC}_{2} \mathrm{H}_{x}(4 \leq x \leq 7)$ are ejected when W wires treated with silacyclobutane are heated in the presence of pure $\mathrm{H}_{2}$ [7]. It should be noted that they checked the recovery of the aged wires after $\mathrm{H}_{2}$ etching, excluding the possible formation of $\mathrm{SiH}_{4}$ and other species from $\mathrm{H}$ atoms and silicon/carbon compounds deposited on chamber walls. Since no such species could be observed in the absence of $\mathrm{H}_{2}$, chemical processes on the wire surfaces must play key roles in the production of $\mathrm{SiH}_{4}, \mathrm{SiCH}_{x}$, and $\mathrm{SiC}_{2} \mathrm{H}_{x}$. These processes must be similar in the release of $\mathrm{BH}_{x}$. 


\section{Conclusions}

A novel technique for surface doping of B atoms without the use of explosive boron compounds is presented. In this technique, metal wires are used as sinks and sources of $\mathrm{B}$ atoms. $\mathrm{B}$ atoms are released by heating metal wires boronized by a mixture of $\mathrm{H}_{2}$ and $\mathrm{H}_{3} \mathrm{NBH}_{3}$ or $(\mathrm{BH})_{3}(\mathrm{NH})_{3}$. The B-atom density in the gas phase was on the order of $10^{11} \mathrm{~cm}^{-3}$, which is enough for surface doping. $\mathrm{N}$-atom contamination can be avoided by placing substrates after the boronization process, since the metal wires are not nitrided. In addition to $\mathrm{W}$, Mo and Ta also can be used as sinks and sources, but the release was the most stable with $\mathrm{W}$ and continued more than several hours after the wires were boronized for $1 \mathrm{~h}$. B-atom density increased with the partial pressure of $\mathrm{H}_{2}$, but the density in pure He systems was still $1 / 5$ of that in the presence of a $\mathrm{H}_{2}$ flow of $20 \mathrm{sccm}$ for W. It is possible to dope B atoms to Si substrates without etching by $\mathrm{H}$ atoms under such conditions. This technique may further be used for deposition, if exposure for a long time is allowed.

\section{Acknowledgments}

This work was supported by CREST, JST and JSPS KAKENHI Grant Number 26410010. 


\section{REFERENCES}

[1] H.F. Winters, H. Seki, R.R. Rye, M.E. Coltrin, Interaction of hydrogen, methane, ethylene, and cyclopentane with hot tungsten: implications for the growth of diamond films, J. Appl. Phys. 76 (1994) 1228-1243.

[2] C.J. Oliphant, C.J. Arendse, G.F. Malgas, D.E. Motaung, T.F.G. Muller, S. Halindintwali, B.A. Julies, D. Knoesen, Filament poisoning at typical carbon nanotube deposition conditions by hot-filament CVD, J. Mater. Sci. 44 (2009) 2610-2616.

[3] Y.J. Shi, L. Tong, B.D. Eustergerling, X.M. Li, Silicidation and carburization of the tungsten filament in HWCVD with silacyclobutane precursor gases, Thin Solid Films 519 (2011) 4442-4446.

[4] Y. Shi, Hot wire chemical vapor deposition chemistry in the gas phase and on the catalyst surface with organosilicon compounds, Acc. Chem. Res. 48 (2015) 163-173.

[5] I. Badran, W.H. Kan, Y.J. Shi, Structural changes in tungsten and tantalum wires in catalytic chemical vapor deposition using 1,3-disilacyclobutane, J. Phys. Chem. C 119 (2015) 19134-19142.

[6] J.K. Holt, M. Swiatek, D.G. Goodwin, H.A. Atwater, The aging of tungsten filaments and its effect on wire surface kinetics in hot-wire chemical vapor deposition, J. Appl. Phys. 92 (2002) 4803-4808.

[7] L. Tong, C.E. Sveen, Y. Shi, Study of tungsten filament aging in hot-wire chemical vapor deposition with silacyclobutane as a source gas and the $\mathrm{H}_{2}$ etching effect, J. Appl. Phys. 103 (2008) 123534/1-123534/6.

[8] K. Honda, K. Ohdaira, H. Matsumura, Study of silicidation process of tungsten catalyzer during silicon film deposition in catalytic chemical vapor deposition, Jpn. J. Appl. Phys. 47 (2008) 3692-3698. 
[9] K. Honda, K. Ohdaira, H. Matsumura, A novel method for suppressing silicidation of tungsten catalyzer during silane decomposition in Cat-CVD, Thin Solid Films 516 (2008) 826-828.

[10] C.E. Sveen, Y. Shi, Effect of filament temperature and deposition time on the formation of tungsten silicide with silane, Thin Solid Films 519 (2011) 4447-4450.

[11] O. Nos, P.A. Frigeri, J. Bertomeu, Real-time monitoring of the silicidation process of tungsten filaments at high temperature used as catalysers for silane decomposition, Mater. Chem. Phys. 143 (2014) 881-888.

[12] H. Umemoto, S.G. Ansari, T. Morimoto, S. Setoguchi, H. Uemura, H. Matsumura, Catalytic CVD processes of oxidizing species and the prevention of oxidization of heated tungsten filaments by $\mathrm{H}_{2}$, Thin Solid Films 516 (2008) 829-831.

[13] Z.S. Houweling, J.W. Geus, R.E.I. Schropp, Synthesis of $\mathrm{WO}_{3}$ nanogranular thin films by hot-wire CVD, Chem. Vapor Deposition 16 (2010) 179-184.

[14] Z.S. Houweling, P.-P.R.M.L. Harks, Y. Kuang, C.H.M. van der Werf, J.W. Geus, R.E.I. Schropp, Hetero- and homogeneous three-dimensional hierarchical tungsten oxide nanostructures by hot-wire chemical vapor deposition, Thin Solid Films 575 (2015) 76-83.

[15] D.W. Comerford, A. Cheesman, T.P.F. Carpenter, D.M.E. Davies, N.A. Fox, R.S. Sage, J.A. Smith, M.N.R. Ashfold, Y.A. Mankelevich, Experimental and modeling studies of $B$ atom number density distributions in hot filament activated $\mathrm{B}_{2} \mathrm{H}_{6} / \mathrm{H}_{2}$ and $\mathrm{B}_{2} \mathrm{H}_{6} / \mathrm{CH}_{4} / \mathrm{H}_{2}$ gas mixtures, J. Phys. Chem. A 110 (2006) 2868-2875.

[16] H. Umemoto, T. Kanemitsu, A. Tanaka, Production of B atoms and BH radicals from $\mathrm{B}_{2} \mathrm{H}_{6} / \mathrm{He} / \mathrm{H}_{2}$ mixtures activated on heated W wires, J. Phys. Chem. A 118 (2014) $5156-5163$. 
[17] H. Umemoto, A. Miyata, A clean source of B atoms without using explosive boron compounds, Bull. Chem. Soc. Jpn. 89 (2016) 899-901.

[18] H. Matsumura, T. Hayakawa, T. Ohta, Y. Nakashima, M. Miyamoto, T.C. Thi, K. Koyama, K. Ohdaira, Cat-doping: Novel method for phosphorus and boron shallow doping in crystalline silicon at $80{ }^{\circ} \mathrm{C}$, J. Appl. Phys. 116 (2014) 114502/1-114502/10.

[19] T. Ohta, K. Koyama, K. Ohdaira, H. Matsumura, Low temperature boron doping into crystalline silicon by boron-containing species generated in Cat-CVD apparatus, Thin Solid Films 575 (2015) 92-95.

[20] J. Seto, K. Ohdaira, H. Matsumura, Catalytic doping of phosphorus and boron atoms on hydrogenated amorphous silicon films, Jpn. J. Appl. Phys. 55 (2016) 04ES05/1-04ES05/4.

[21] H. Umemoto, A. Miyata, T. Nojima, Decomposition processes of $\mathrm{H}_{3} \mathrm{NBH}_{3}$ (borazane), $(\mathrm{BH})_{3}(\mathrm{NH})_{3}$ (borazine), and $\mathrm{B}\left(\mathrm{CH}_{3}\right)_{3}$ (trimethylboron) on heated $\mathrm{W}$ wire surfaces, Chem. Phys. Lett. 639 (2015) 7-10.

[22] R.R. Rye, Hot filament activated chemical vapor deposition of boron nitride, J. Vac. Sci. Tech. A 9 (1991) 1099-1103.

[23] H. Matsumura, K. Kamesaki, A. Masuda, A. Izumi, Catalytic chemical sputtering: A novel method for obtaining large-grain polycrystalline silicon, Jpn. J. Appl. Phys. 40 (2001) L289-L291.

[24] K. Kamesaki, A. Masuda, A. Izumi, H. Matsumura, Proposal of catalytic chemical sputtering method and its application to prepare large grain size poly-Si, Thin Solid Films 395 (2001) 169-172.

[25] H. Umemoto, A. Miyata, Decomposition processes of diborane and borazane (ammonia-borane complex) on hot wire surfaces, Thin Solid Films 595 (2015) 
231-234.

[26] S. Dorfman, R.R. Braga, K.C. Mundim, D. Fuks, Simulations of initial stages of boron deposition on (1 110$)$ tungsten surface, Surf. Sci. 566-568 (2004) 676-682.

[27] $\mathrm{H}$. Umemoto, Production and detection of $\mathrm{H}$ atoms and vibrationally excited $\mathrm{H}_{2}$ molecules in CVD processes, Chem. Vapor Deposition 16 (2010) 275-290.

[28] M. Márquez-Mijares, B. Lepetit, D. Lemoine, Carbon adsorption on tungsten and electronic field emission, Surf. Sci. 645 (2016) 56-62. 
Figure Captions

Fig. 1. Time dependence of the electric power needed to keep the wire temperature constant at $2.29 \times 10^{3} \mathrm{~K}$ in the presence of $\mathrm{H}_{3} \underline{\mathrm{NBH}_{3}} \underline{\mathrm{H}}_{2} \underline{\text { (open circle) and } \mathrm{NH}_{3}} \underline{\text { (closed }}$

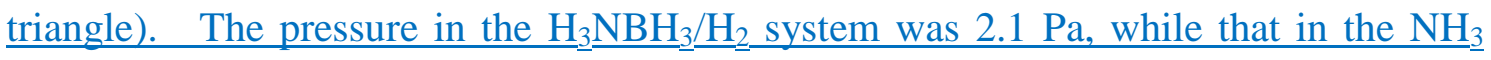
system was $3.3 \mathrm{~Pa}$ when the wire was not heated.

Fig. 2. Time dependence of B-atom densities in the gas phase in the presence of a $\mathrm{H}_{2}$ flow of $20 \mathrm{sccm}$, measured after $\mathrm{W}$ wires were boronized by $\mathrm{H}_{3} \mathrm{NBH}_{3} / \mathrm{H}_{2}$ (closed circle), $(\mathrm{BH})_{3}(\mathrm{NH})_{3}, / \mathrm{H}_{2}$ (closed triangle), or $\mathrm{B}_{2} \mathrm{H}_{6} / \mathrm{H}_{2}$ (closed square). Boronization was carried out for 60 min with $2.1 \mathrm{~Pa}$ of $\mathrm{H}_{2}$, while the B-atom densities were measured in the presence of $2.1 \mathrm{~Pa}$ of $\mathrm{H}_{2}$. The $\mathrm{W}$ wire temperature was kept at $2.29 \times 10^{3} \mathrm{~K}$ during both the boronization and the B-atom density measurement.

Fig. 3. Time dependence of relative B-atom densities in the gas phase in the presence of a $\mathrm{H}_{2}$ flow of $20 \mathrm{sccm}$ measured after the boronization of $\mathrm{W}$ (closed circle), Mo (open circle), and Ta (open square) wires. Boronization was carried out for $60 \mathrm{~min}$ in the presence of $\sim 0.01 \mathrm{~Pa}$ of $\mathrm{H}_{3} \mathrm{NBH}_{3}$ and $2.1 \mathrm{~Pa}$ of $\mathrm{H}_{2}$, while the B-atom densities were measured in the presence of $2.1 \mathrm{~Pa}^{\mathrm{P}} \mathrm{H}_{2}$. The wire temperature was kept at $2.29 \times 10^{3}$ $\mathrm{K}$ during both the boronization and the $\mathrm{B}$-atom density measurement.

Fig. 4. B-atom densities in the gas phase as a function of the reciprocal of boronized wire temperature. Closed circles represent the results for $\mathrm{W}$ measured in the presence of 2.1 $\mathrm{Pa}$ of $\mathrm{H}_{2}$. Open squares represent the results for Ta measured in the presence of 
2.1 $\mathrm{Pa}$ of $\mathrm{H}_{2}$. Open circles represent the results for $\mathrm{W}$ measured in the presence of 2.1 Pa of He. The solid lines are the least-squares fit. 


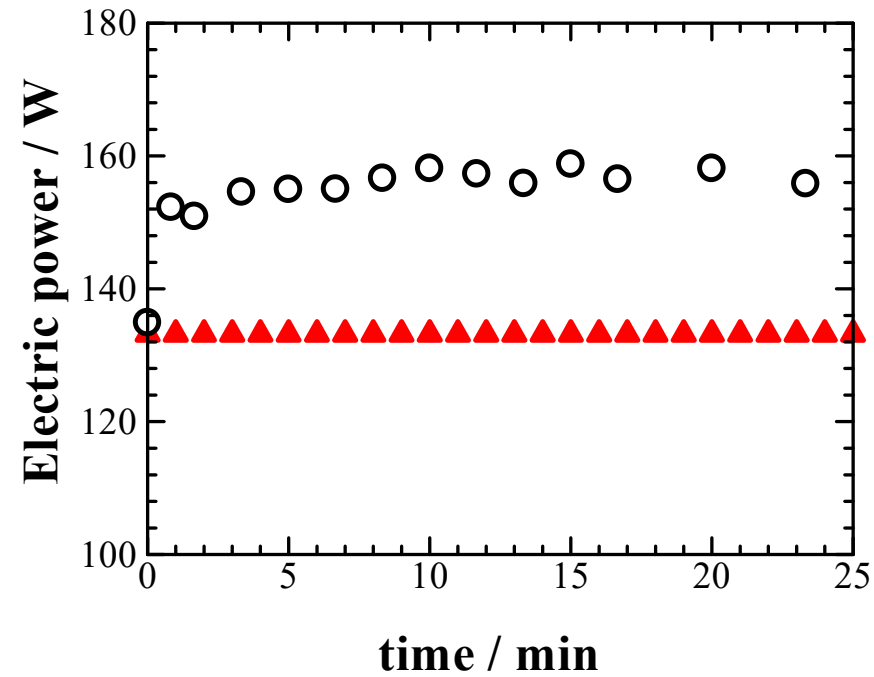


Figures 2
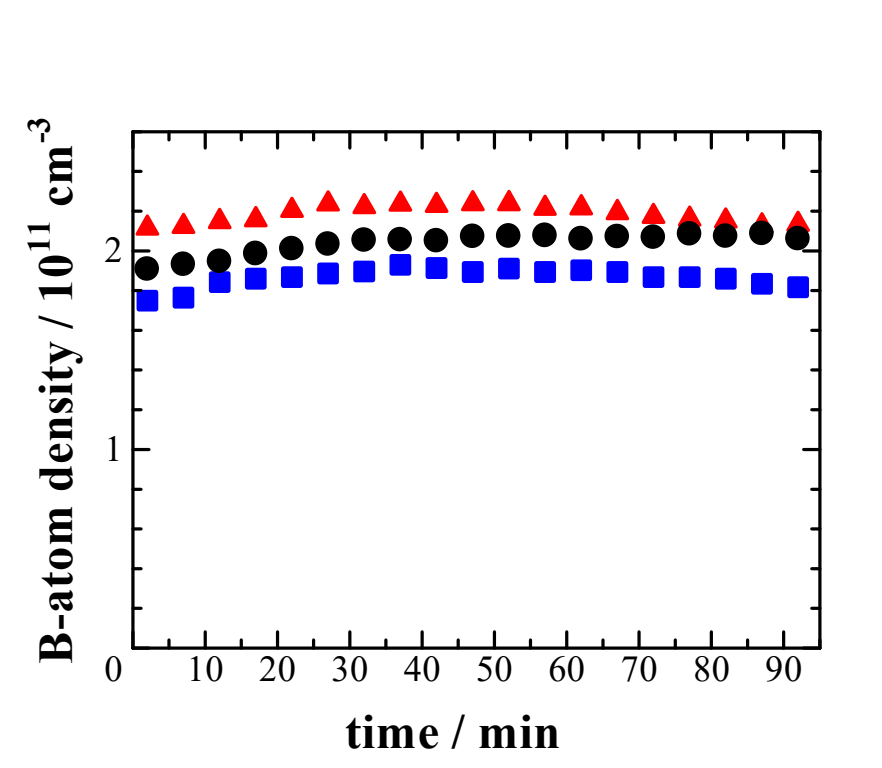


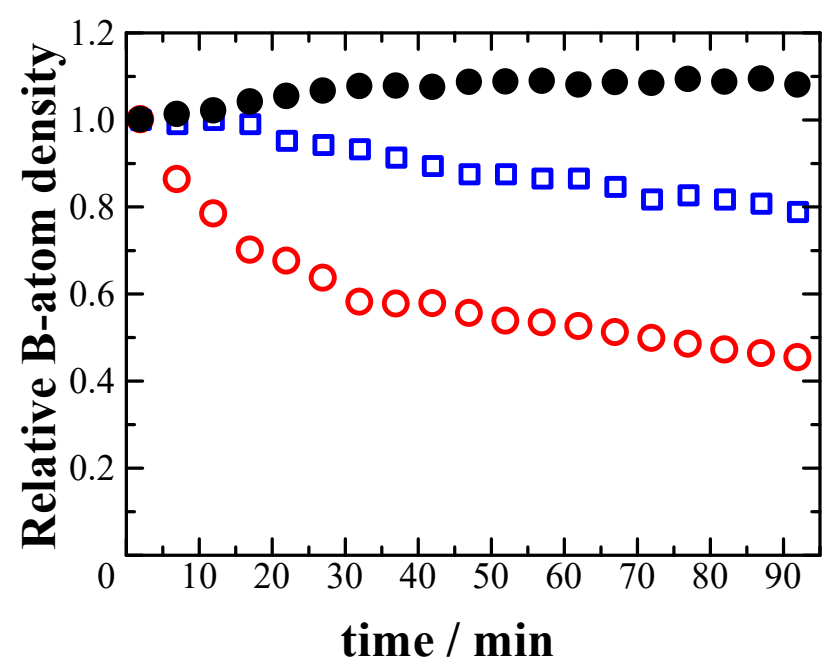


Figures 4

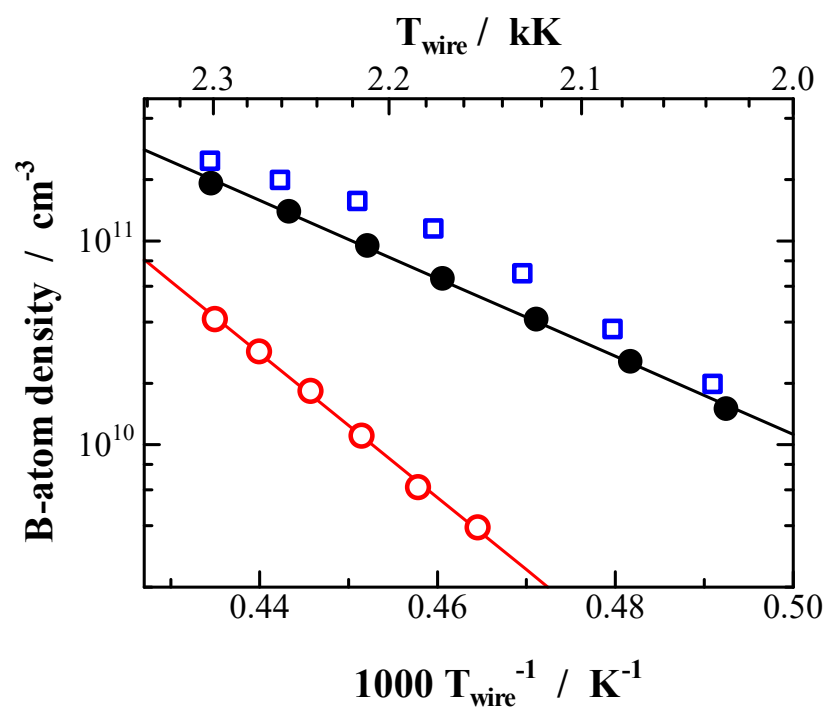

